\title{
Impact of Annealing Treatment on the Behaviour of Titanium Dioxide Nanotube Layers
}

\author{
Marie Siampiringue ${ }^{1}$, Christophe Massard ${ }^{*}$, Eric Caudron'1, Yves Sibaud1, \\ Mohammed Sarakha ${ }^{2,3}$, Komla Oscar Awitor ${ }^{1}$ \\ ${ }^{1}$ Clermont Université, Université d'Auvergne, Clermont-Ferrand, France \\ ${ }^{2}$ Clermont Université, Université Blaise Pascal, Institut de Chimie de Clermont-Ferrand, Clermont-Ferrand, France \\ ${ }^{3}$ Centre National de la Recherche Scientifique, Unité Mixte de Recherches 6296, Institut de Chimie de \\ Clermont-Ferrand, Aubiere, France \\ Email: "christophe.massard@udamail.fr
}

Received 19 February 2016; accepted 25 June 2016; published 28 June 2016

Copyright (C) 2016 by authors and Scientific Research Publishing Inc.

This work is licensed under the Creative Commons Attribution International License (CC BY).

http://creativecommons.org/licenses/by/4.0/

(c) (i) Open Access

\section{Abstract}

In this work, we study the influence of the annealing treatment on the behaviour of titanium dioxide nanotube layers. The heat treatment protocol is actually the key parameter to induce stable oxide layers and needs to be better understood. Nanotube layers were prepared by electrochemical anodization of $\mathrm{Ti}$ foil in $0.4 \mathrm{wt} \%$ hydrofluoric acid solution during 20 minutes and then annealed in air atmosphere. In-situ X-ray diffraction analysis, coupled with thermogravimetry, gives us an inside on the oxidation behaviour of titanium dioxide nanotube layers compared to bulk reference samples. Structural studies were performed at $700^{\circ} \mathrm{C}$ for $12 \mathrm{~h}$ in order to follow the time consequences on the oxidation of the material, in sufficient stability conditions. In-situ XRD brought to light that the amorphous oxide layer induced by anodization is responsible for the simultaneous growths of anatase and rutile phase during the first $\mathbf{3 0}$ minutes of annealing while the bulk sample oxidation leads to the nucleation of a small amount of anatase $\mathrm{TiO}_{2}$. The initial amorphous oxide layer created by anodization is also responsible for the delay in crystallization compared to the bulk sample. Thermogravimetric analysis exhibits parabolic shape of the mass gain for both anodized and bulk sample; this kinetics is caused by the formation of a rutile external protective layer, as depicted by the associated in-situ XRD diffractograms. We recorded that titanium dioxide nanotube layers exhibit a lower mean mass gain than the bulk, because of the presence of an initial amorphous oxide layer on anodized samples. In-situ XRD results also provide accurate information concerning the sub-layers behavior during the annealing treatment for the bulk and nanostructured layer. Anatase crystallites are mainly localized at the interface oxide layer-metal and the rutile is at the external interface. Sample surface topography was characte-

${ }^{*}$ Corresponding author.

How to cite this paper: Siampiringue, M., Massard, C., Caudron, E., Sibaud, Y., Sarakha, M. and Awitor, K.O. (2016) Impact of Annealing Treatment on the Behaviour of Titanium Dioxide Nanotube Layers. Journal of Biomaterials and Nanobiotechnology, 7, 142-153. http://dx.doi.org/10.4236/jbnb.2016.73015 
rized using scanning electron microscopy (SEM). As a probe of the photoactivity of the annealed $\mathrm{TiO}_{2}$ nanotube layers, degradation of an acid orange 7 (A07) dye solution and 4-chlorophenol under UV irradiation (at $365 \mathrm{~nm}$ ) were performed. Such titanium dioxide nanotube layers show an efficient photocatalytic activity and the analytical results confirm the degradation mechanism of the 4-chlorophenol reported elsewhere.

\section{Keywords}

\section{Titanium Dioxide Nanotubes, In-Situ X-Ray Diffraction, Annealing Treatment, Photo-Degradation}

\section{Introduction}

Researches on the synthesis and characterization of nanomaterial are in booming development nowadays since the initial definition of Richard P. Feynman in 1959 [1]. The characteristic size of these materials, in the nanometer range, induces novel electronic, optical and mechanical properties and opens the way to the development of a wide variety of applications from the medical field [2] to electric batteries [3]. Among all the classes of nanomaterials, the nanostructured transitional metal oxides such as nanowires, nanorods, and nanotubes have gained considerable interest considering the advantages of self-ordered metal oxide nanotube arrays on metal substrates [4]. Especially, titanium dioxide nanotube layers are very interesting platforms in order to develop research and applications in nanotechnology [5] [6]. Numerous studies are dedicated to the understanding of the nanotube layers' formation [7]-[9]. After electrochemical anodization of Ti foils, amorphous titanium dioxide nanotube layers are obtained [10]. Generally, this amorphous structure is too disordered, induces a lack of electronic properties and is not convenient for the applications. Thermal treatments are performed in a variety of atmosphere. In air, a mixture of anatase and rutile is primarily obtained [11]. In order to develop photovoltaic applications, anatasetitania phase is researched [12]. Under annealing treatment, anatase and rutile are the primary crystal structures obtained but a formation of brookite crystallites is reported between $470^{\circ} \mathrm{C}$ and $500^{\circ} \mathrm{C}$ in air [13]. In order to better understand the crystallization behaviour of titanium oxide nanotube arrays under annealing, in-situ X-ray diffraction is an efficient analytical tool [14]. In our work, we use in-situ X-ray diffraction analysis, coupled with thermogravimetry, to study the oxidation behaviours of titanium dioxide nanotube layers compared to bulk reference samples. These investigations are in extension of our already published work [15], concerning the evaluation of the photocatalytic activity versus the annealing temperature. In this previous work, we found that the annealing treatment at $400^{\circ} \mathrm{C}$ was the most efficient, relative to a photodegradation kinetics. The novelty of the present study is that we take into account the stability of the annealed samples. Especially, the kinetics of the crystallographic phase's transformation is of primary importance. Precisely, we focused on the annealing time in isothermal condition in order to investigate the layers evolution. A comparison has been done between nanostructured and bulk samples taken as reference. Photocatalytic tests were performed as a probe to assess the crystallinity of the annealed material. The mineralization of organic compounds using photo-induced reactions is a major issue for the decontamination of groundwater and wastewater submitted to organic pollutants. Titania photooxidation of organic species involves reactive oxygen species (ROS) [16]. We investigated the photocatalytic activity of our $\mathrm{TiO}_{2}$ nanotube layers by monitoring the degradation of an acid orange 7 (AO7) dye solution and 4-chlorophenol under UV irradiation. Experimental results showed an efficient photoactivity of the nanostructured surfaces. Analytical monitoring of the by-products of 4-chlorophenol degradation confirms the degradation mechanism reported previously [17].

\section{Experimental Section}

\subsection{Chemical}

4-Chlorophenol (4-CP) was purchased from Sigma. Acid Orange 7 (AO7) was purchased from Acros Organic. Benzoquinone and hydroquinone were purchased from Fluka. They were all used without further purifications. Methanol (HPLC grade), formic acid ( $\geq 95 \%$ ), acetone and trichloroethylene were purchased from Sigma Aldrich. Stock solutions containing the desired concentrations of 4-chlorophenol (4-CP), hydroquinone (HQ) and 
benzoquinone (BQ) were prepared in Milli-Q water.

\subsection{Synthesis of Nanotube Layer}

To fabricate anodic $\mathrm{TiO}_{2}$ nanotube layers, we used Ti foil (Goodfellow, 99.6\% purity) with a thickness of $25 \mu \mathrm{m}$. The Ti foil was degreased by successive sonification in trichloroethylene, acetone, and methanol, followed by rinsing with de-ionized water and blown dry with nitrogen. Anodization was carried out at room temperature $\left(20^{\circ} \mathrm{C}\right)$ in $0.4 \mathrm{wt} \% \mathrm{HF}$ aqueous solution with the anodizing voltage maintained at $20 \mathrm{~V}$ [18]. The surface area of the anodized samples was approximatively $1.05 \mathrm{~cm}^{2}$.

\subsection{Surface Characterization}

The surface topography characterization of the anodized Ti foil was performed using a Zeiss Supra 55 VP scanning electron microscope (SEM) with secondary emission and in lens detectors. The accelerating voltage and the working distance were $3 \mathrm{kV}$ and $5 \mathrm{~mm}$, respectively.

\subsection{Heat Treatment Protocol}

High temperature studies were performed for $12 \mathrm{~h}$ at $700^{\circ} \mathrm{C}$ in air using a Setaram TGDTA 92-1600 micro thermobalance for mass gain and a high temperature Anton PAAR HTK 1200 chamber with integrated sample spinner in a Philips X'pert MPD diffractometer for X-ray diffraction studies. The annealing condition (12 h at $700^{\circ} \mathrm{C}$ ) was chosen to promote the complete formation of rutile crystalline phase which is considered to be the most thermodynamically stable bulk phase in comparison with other possible $\mathrm{TiO}_{2}$ crystalline phases which are respectively anatase and brookite (obtained at lower annealing temperatures) as underlined by several authors [19] [20].

\subsection{Irradiation System}

For the photocatalysis studies, the irradiations were carried out in monochromatic parallel beam in $1 \mathrm{~cm}$ (path length) quartz cell. The light source was a mercury lamp (200 W) equipped with an Oriel monochromator. The monochromatic irradiation was set at wavelength $365 \mathrm{~nm}$ (Figure 1). The light intensity was measured by ferrioxalate actinometry [21]. The photon flux of the monochromatic irradiation was measured at $4.10 \times 10^{15}$ photon $\cdot \mathrm{s}^{-1} \cdot \mathrm{cm}^{-2}\left(23.8 \mathrm{~W} / \mathrm{m}^{2}\right)$.

\subsection{Analytical Study}

The photo-catalytic decomposition of 4-CP solution was monitored by the decrease of the solution's absorbance at $280 \mathrm{~nm}$ (maximum absorption band of the 4-CP solution), using a Waters HPLC system. The HPLC system was equipped with a diode array (type 996) UV-Vis detector, an automatic injector (type 717), two pumps (type 600). To investigate the degradation of 4-CP under UV irradiation (365 nm), experiments were performed using a reverse phase Agilent column (Eclipse XDB $\mathrm{C}_{8}, 250 \mathrm{~mm} \times 4.6 \mathrm{~mm}, 5 \mu \mathrm{m}$ ). For analyses using HPLC, the elution was accomplished by water with formic acid $(0.3 \%)$ and methanol $(65 / 25, \mathrm{v} / \mathrm{v})$ with flow rate of 1.0 $\mathrm{mL} / \mathrm{min}$ and the injection volume was $30 \mu \mathrm{L}$.

Photodegradation of $\mathrm{AO} 7$ was also used as a probe to assess the photo-activity of the $\mathrm{TiO}_{2}$ layers. $\mathrm{AO} 7$ con-

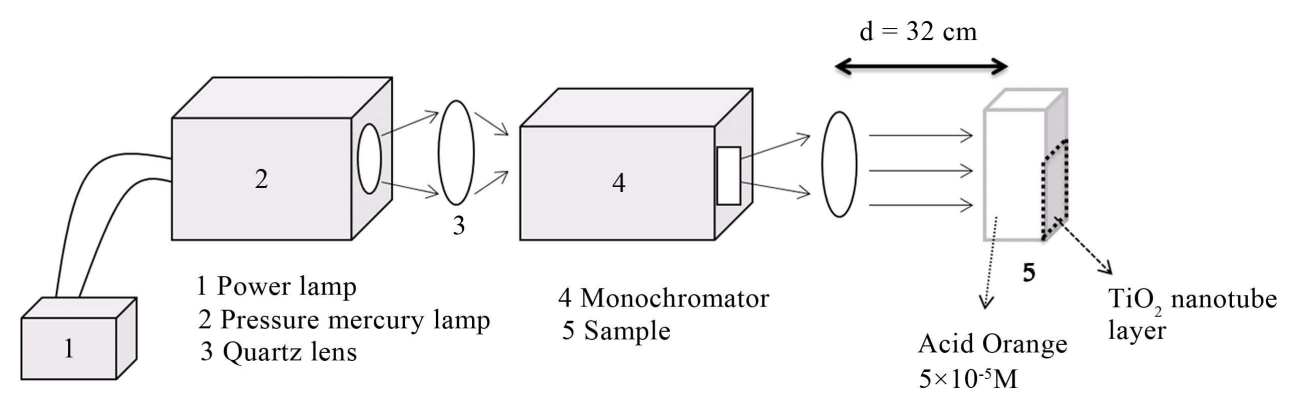

Figure 1. Scheme of the monochromatic irradiation device. 
taining azo bond is a model molecule commonly used to perform photocatalytic tests to simulate azo dyes wastewater pollutants coming from industries. Photo-catalytic experiments were conducted in aqueous solution of AO7 (from Acros Organics, also called Orange II) with a concentration of $5.0 \times 10^{-5} \mathrm{~mol} \cdot \mathrm{L}^{-1}$, placed in a cylindrical glass reactor equipped with a magnetic stirrer. The glass reactor was irradiated with polychromatic fluorescent UV lamps (Philips TDL $8 \mathrm{~W}$ ) (total optical power, $1.3 \mathrm{~W}$ ), in a configuration providing about 0.35 $\mathrm{mW} / \mathrm{cm}^{2}$ at the sample surface. The photodegradation kinetics was recorded by assaying the AO7 solution submitted to different UV irradiation time using a Perkin Elmer lambda 35 UV spectrophotometer. Quartz glass cells with an optical pathway of $1 \mathrm{~cm}$ were used. De-ionized water was taken as reference. The photodegradation of the dye was followed by monitoring the decrease of the solution's absorbance at $483 \mathrm{~nm}$ (strong absorption band of the Acid Orange 7).

\section{Results and Discussion}

\section{1. $\mathrm{TiO}_{2}$ Nanotube Layer Characteristics}

Figure 2 shows SEM images of the $\mathrm{TiO}_{2}$ nanotubes obtained by anodizing a Ti foil. We observe ordered nanotube arrays grown on top of the Ti foil with an oxide barrier layer separating the nanotubes from the titanium foil. Figure 2(a) shows the top down image of the ordered array of $\mathrm{TiO}_{2}$ nanotube layers with a mean diameter of approximately $100 \mathrm{~nm}$. Figure 2(b) shows an oblique view of the $\mathrm{TiO}_{2}$ nanotubes. The tube length determined by accounting for foreshortening from this image was found to be approximately $430 \mathrm{~nm}$.

\subsection{Thermogravimetric Study}

Three anodized and three bulk samples (total surface areas $3 \mathrm{~cm}^{2}$ : and thicknesses: $25 \mu \mathrm{m}$ ) were tested by thermogravimetry to clearly observe the anodization effect on oxidation behaviour at $700^{\circ} \mathrm{C}$ for $12 \mathrm{~h}$. Figure 3 shows the mean mass gain versus time curves, for anodized and bulk reference titanium oxidized for $12 \mathrm{~h}$ at $700^{\circ} \mathrm{C}$ under air.

This figure shows that both anodized and bulk samples exhibit parabolic oxidation rates due to the formation of a protective oxide layer near the surface (theses oxidation curves are characteristic of a diffusion of species limited by the growing oxide layer). Figure 3 also suggests that titanium anodization process promotes the formation of an initial protective $\mathrm{TiO}_{2}$ nanotubes layer because anodized samples exhibit a lower mean mass gain versus time curve than those of bulk reference samples during the same annealing process. These results are in good agreement with several works showing the presence of $\mathrm{TiO}_{2}$ nanotubes after anodization if the titanium foil is exposed to a sufficiently anodic voltage, in a particular electrochemical configuration, with an appropriate electrolyte composition, promoting the metal dissolution by oxidation reaction $\left(\mathrm{M} \rightarrow \mathrm{M}^{\mathrm{n}+}+\mathrm{ne}^{-}\right)$[22]. It is important to note that high oxidation rates were mainly observed during the first $5 \mathrm{~h}$ or $6 \mathrm{~h}$ of the annealing process (formation of a continuous protective $\mathrm{TiO}_{2}$ layer) for both anodized and bulk reference samples. These results have prompted us to carry out in-situ high temperature X-ray diffraction studies in order to understand the

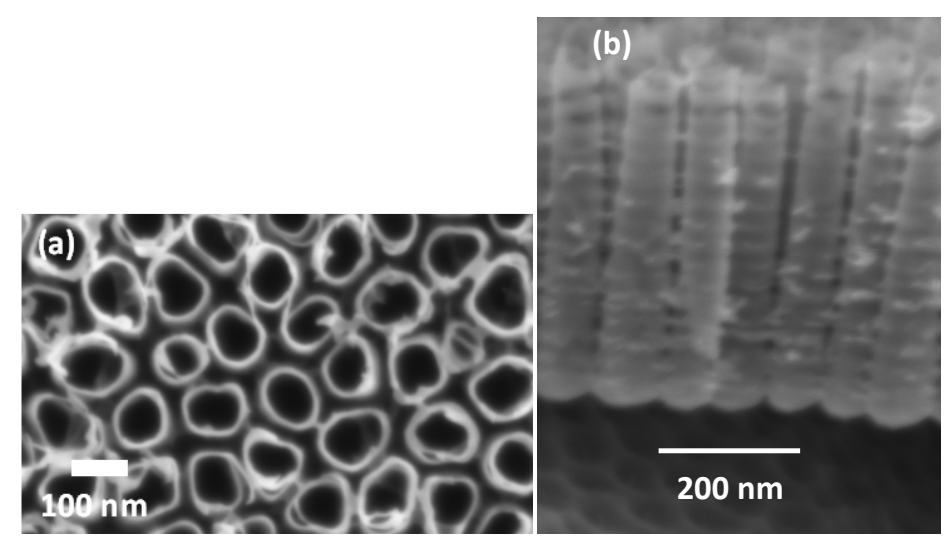

Figure 2. SEM images of the $\mathrm{TiO}_{2}$ nanotubes obtained by anodizing a Ti foil. (a) Top down image of the ordered array of $\mathrm{TiO}_{2}$ nanotube layers with a mean diameter of approximately $100 \mathrm{~nm}$; (b) An oblique view of the $\mathrm{TiO}_{2}$ nanotubes. The tube length determined from this image was found to be approximately $430 \mathrm{~nm}$. 


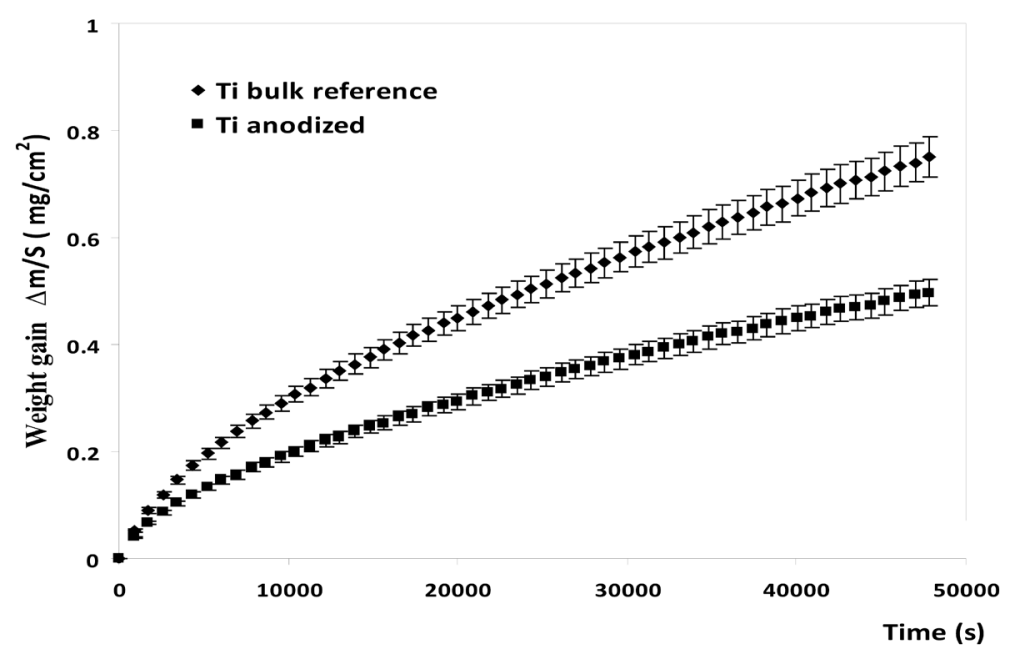

Figure 3. Mean mass gain vs. time curves of anodized and bulk reference titanium samples $\left(\mathrm{T}=700^{\circ} \mathrm{C}, 12 \mathrm{~h}\right.$ in air).

different mass gain curve evolutions obtained by thermogravimetry in the case of anodized and bulk references samples.

\subsection{In-Situ High Temperature X-Ray Diffraction Characterization of Bulk Reference Samples}

In-situ high temperature $\mathrm{X}$-ray diffraction analyses $\left(\mathrm{T}=700^{\circ} \mathrm{C}\right.$ in air) were performed, using the $\mathrm{CuK}_{\alpha 1}=1.5406$ $\AA$ radiation, every 30 minutes for 12 hours on both anodized and bulk titanium samples to observe the initial nucleation stage of new compounds induced by the heat treatment.

Figure 4 allows to determine that the initial bulk reference sample (before heat treatment) match with the hexagonal compact structure namely Ti $\alpha$ structure (JCPDS 44-1294). The initial samples were laminated (by Goodfellow) with the (002) preferential crystallographic orientation $\left(2 \theta=38.421^{\circ}\right)$ because the main peak (Relative intensity: $100 \%$ ) of Ti $\alpha$ powder is in fact at $2 \theta=40.170^{\circ}$ with the (101) preferential orientation. All peaks detected ( $2 \theta$ diffraction angles) on initial reference samples correspond to the main diffraction peaks (relative intensities higher than 10\%) observed in the case of the Ti $\alpha$ hexagonal compact structure. This figure shows the initial nucleation stage of small amounts of anatase $\mathrm{TiO}_{2}$ (JCPDS 21-1272) during the first 30 min of heat treatment with the $(004)$ preferential orientation $\left(2 \theta=37.800^{\circ}\right)$ induced by the $(002)$ preferential orientation of the titanium bulk sample. After the first $30 \mathrm{~min}$ the rutile $\mathrm{TiO}_{2}$ (JCPDS 21-1276) is also detected with (110) preferential orientation (corresponding to the main rutile characteristic peak $\left(2 \theta=27.446^{\circ}\right.$; relative intensity: $\left.100 \%\right)$ ) which is independent of the orientation of the titanium bulk sample. Moreover, after the first hour of heat treatment the evolution of the asymmetric peak near $2 \theta=38^{\circ}$ which corresponds in fact to the overlapping of anatase $\left(2 \theta=37.800^{\circ}\right)$ and titanium $\left(2 \theta=38.421^{\circ}\right)$ peaks clearly indicates the growth of anatase phase (increasing peak) on titanium bulk sample (decreasing peak). This figure also underlines the continuous growth of the rutile phase during the first $2 \mathrm{~h} 30$ of the heat treatment by the increase of the number of characteristic peaks and the increase in their intensities.

In-situ high temperature X-ray diffraction analyses performed between $2 \mathrm{~h}$ and $5 \mathrm{~h}$ (Figure 5) show increases in intensity only for the rutile characteristic peaks. These results suggest that anatase crystallites are mainly localized at the interface oxide layer-metal and the rutile layer is at the external interface.

$\mathrm{X}$-ray diffraction analyses performed between $4 \mathrm{~h} 30$ and $7 \mathrm{~h} 30$ (Figure 6) suggest the formation of a protective rutile layer because rutile characteristic peak intensities increase slowly and consequently no significant peak intensity evolutions were observed for the sublayers (i.e.: anatase and titanium). Same conclusions could be done concerning X-ray diffraction analyses performed between $7 \mathrm{~h}$ and $12 \mathrm{~h}$. In-situ X-ray diffraction results are in good agreement with thermogravimetric analyses performed on titanium bulk samples (Figure 3), showing a decrease of the oxidation rate after $5 \mathrm{~h}$ of annealing (suggesting the formation of a continuous protective oxide layer). 


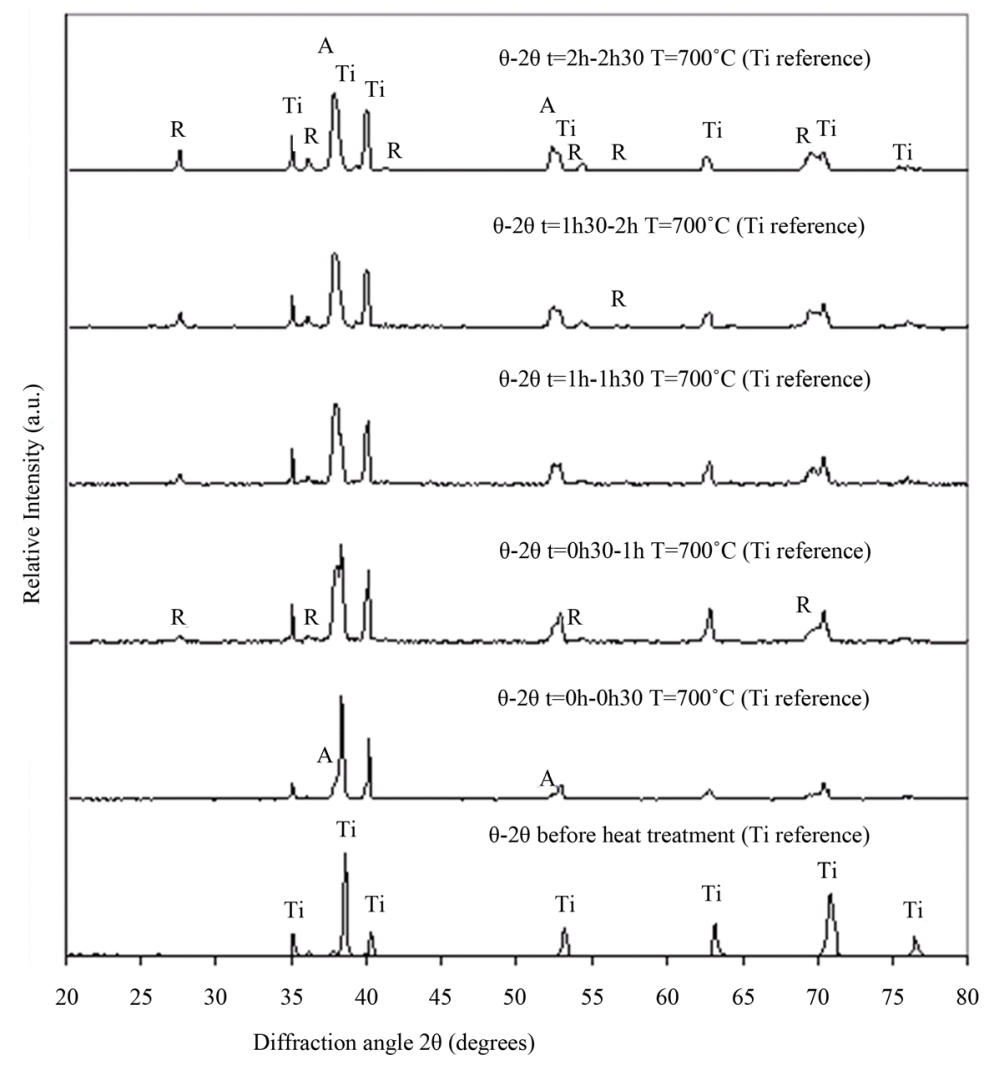

Figure 4. Initial sample and in-situ high temperature first 2 h 30 min XRD experimental diffractograms performed on titanium bulk reference sample at $\mathrm{T}=700^{\circ} \mathrm{C}$ in air (Ti: titanium, A: anatase, R: rutile).

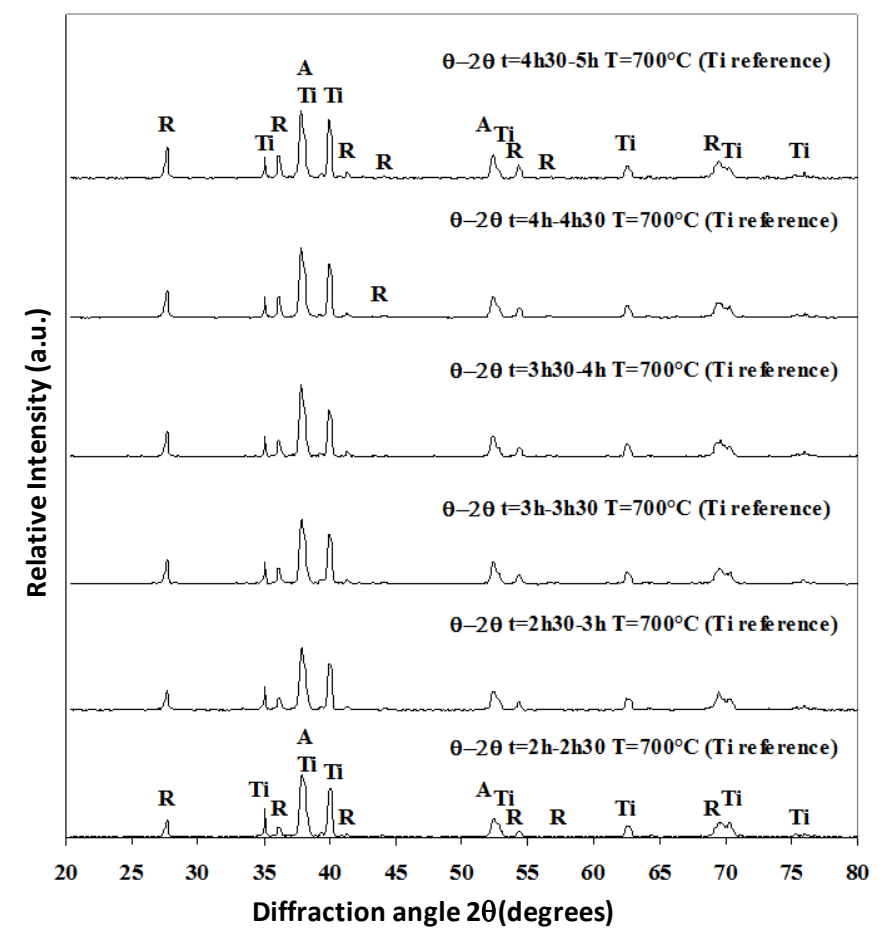

Figure 5. In-situ high-temperature XRD experimental diffractograms performed on titanium bulk reference sample annealed at $\mathrm{T}=700^{\circ} \mathrm{C}$ in air (Ti: titanium, A: anatase, R: rutile) from $2 \mathrm{~h}$ to $5 \mathrm{~h}$. 


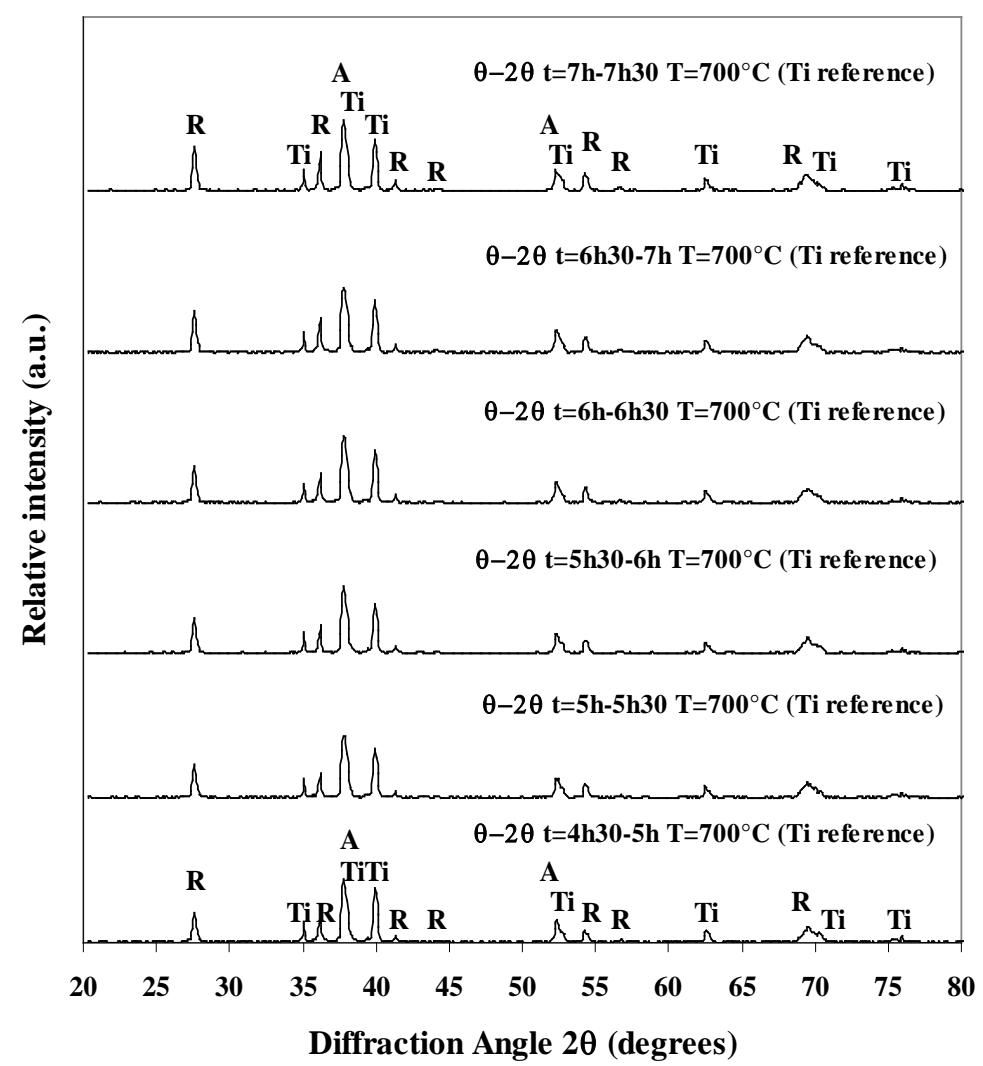

Figure 6. In-situ high-temperature XRD experimental diffractograms performed on titanium bulk reference sample annealed at $\mathrm{T}=700^{\circ} \mathrm{C}$ in air (Ti: titanium, A: anatase, R: rutile) from $4 \mathrm{~h} 30$ to $7 \mathrm{~h} 30$.

\subsection{In-Situ High Temperature X-Ray Diffraction Characterization of Anodized Samples}

In-situ high temperature X-ray diffraction analyses performed on titanium anodized sample during the first $2 \mathrm{~h}$ 30 of annealing are given in Figure 7.

X-ray diffraction analyses obtained before heat treatment and thermogravimetric results suggest that anodization process promotes in fact the formation of an amorphous oxide layer on nanotube surface as underlined by several works on anodized titanium [23] [24]. This amorphous oxide layer induces two phenomena during the first 30 minutes of annealing (in comparison with bulk reference sample (Figure 4)): firstly the simultaneous growths of anatase and rutile phases and secondly the rutile and anatase initial nucleation stage with their normal crystallographic growth orientations (anatase (101) at $2 \theta=25.281^{\circ}$ and rutile (110) at $2 \theta=27.446^{\circ}$ ) are independent of laminated titanium bulk (002) preferential orientation. After the first 30 min of annealing, X-ray analyses show an important increase in intensity of the main rutile (110) characteristic peak which seems to suggest a delay to crystallise the initial amorphous oxide layer.

It is important to note that the high intensity of the rutile X-ray diffraction peak is due to the crystallisation of the amorphous layer all along nanotube surfaces (anodization promoting a highest surface area compared to bulk sample) rather than the growth of a thicker oxide layer than those of bulk sample. After one hour of annealing, rutile diffraction peak becomes the highest peak observed on X-ray diffractogram whereas no intensity evolution is observed for the main anatase diffraction peak. These results also suggest that anatase crystallites are mainly localized at the oxide layer-metal interface under the rutile external layer. In-situ high temperature X-ray diffraction analyses show the continuous increase of the main rutile characteristic peak for the first $5 \mathrm{~h}$ of annealing (Figure 7 and Figure 8) as in the case of bulk sample. After the first $5 \mathrm{~h}$ of annealing, no significant evolution of the main rutile characteristic peak is observed (Figure 9). These results are in good agreement with thermogravimetric analyses suggesting the formation of a continuous protective oxide layer. It is important to note that similar anatase main diffraction peak intensities are observed during the $12 \mathrm{~h}$ of annealing which seems to indicate a continuous transformation at the internal interface metal $\rightarrow$ anatase $\rightarrow$ rutile (most stable titanium oxide) 


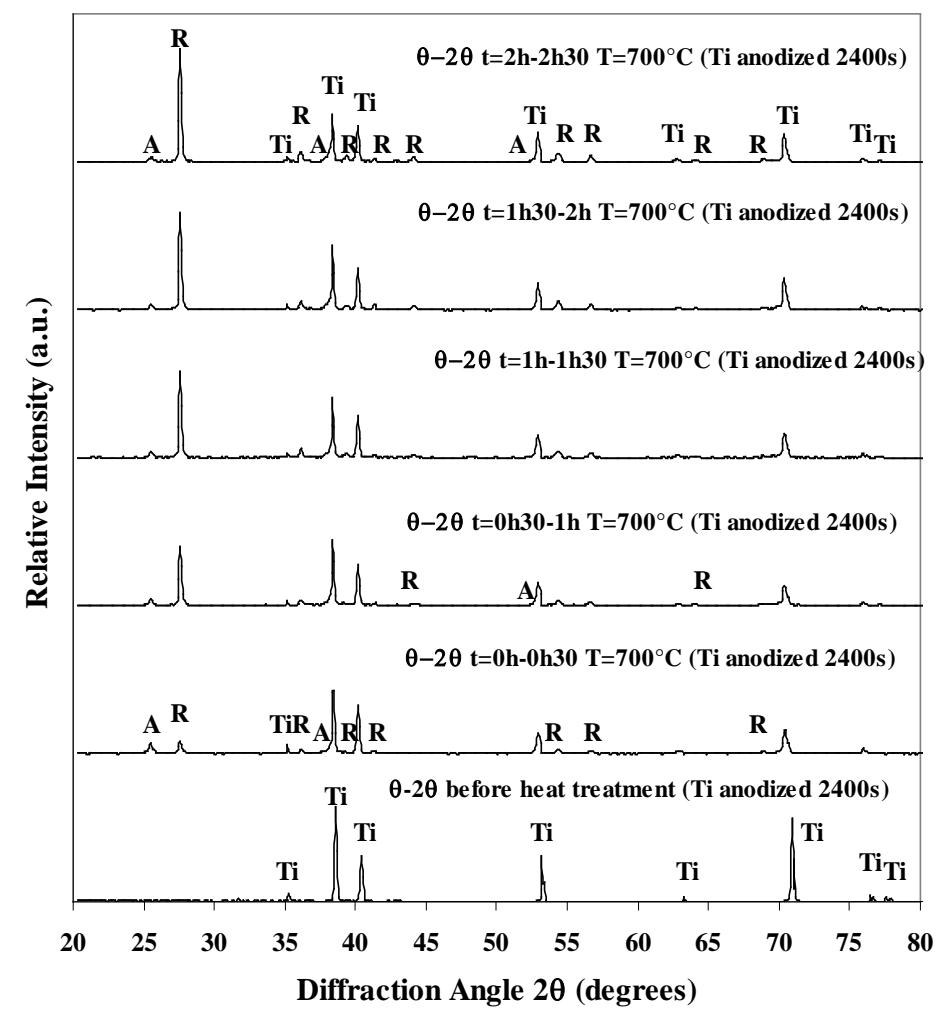

Figure 7. In-situ high-temperature XRD experimental diffractograms performed on titanium anodized sample annealed at $\mathrm{T}=700^{\circ} \mathrm{C}$ in air (Ti: titanium, A: anatase, $\mathrm{R}$ : rutile) from $0 \mathrm{~h}$ to $2 \mathrm{~h} 30$.

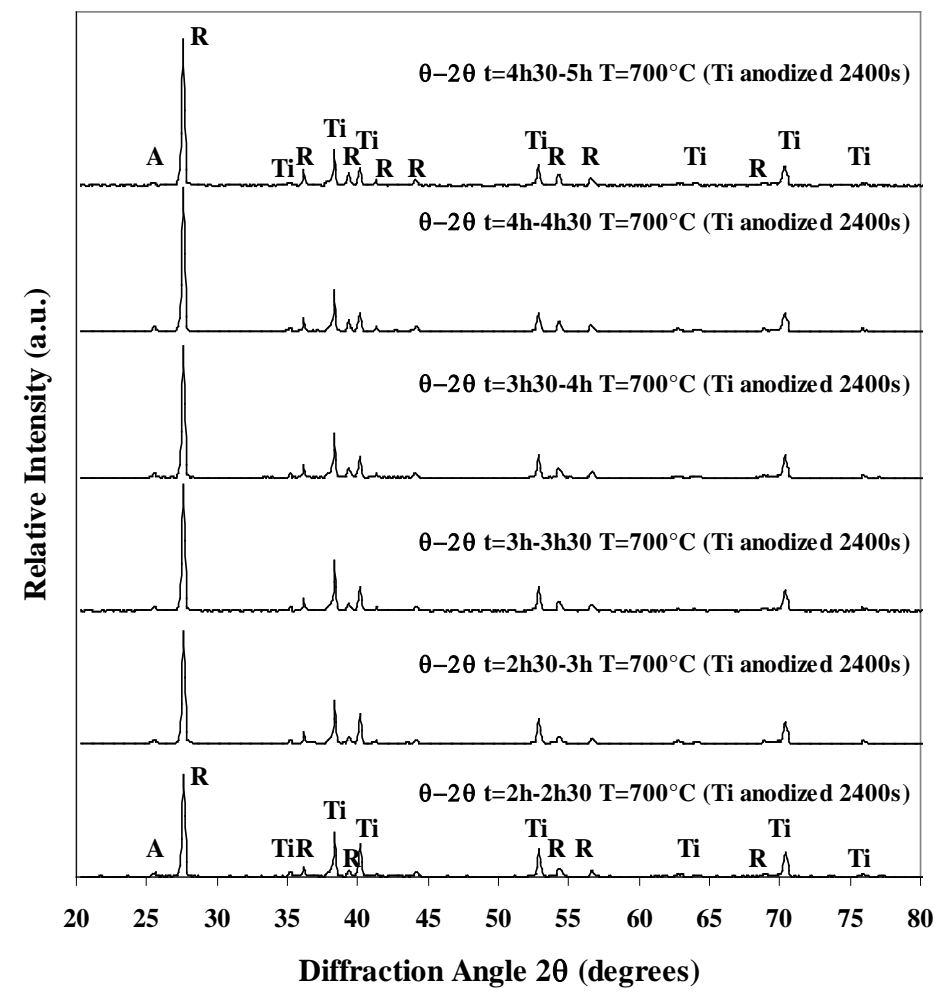

Figure 8. In-situ high-temperature XRD experimental diffractograms performed on titanium anodized sample annealed at $\mathrm{T}=700^{\circ} \mathrm{C}$ in air (Ti: titanium, A: anatase, R: rutile) from $2 \mathrm{~h}$ to $5 \mathrm{~h}$. 


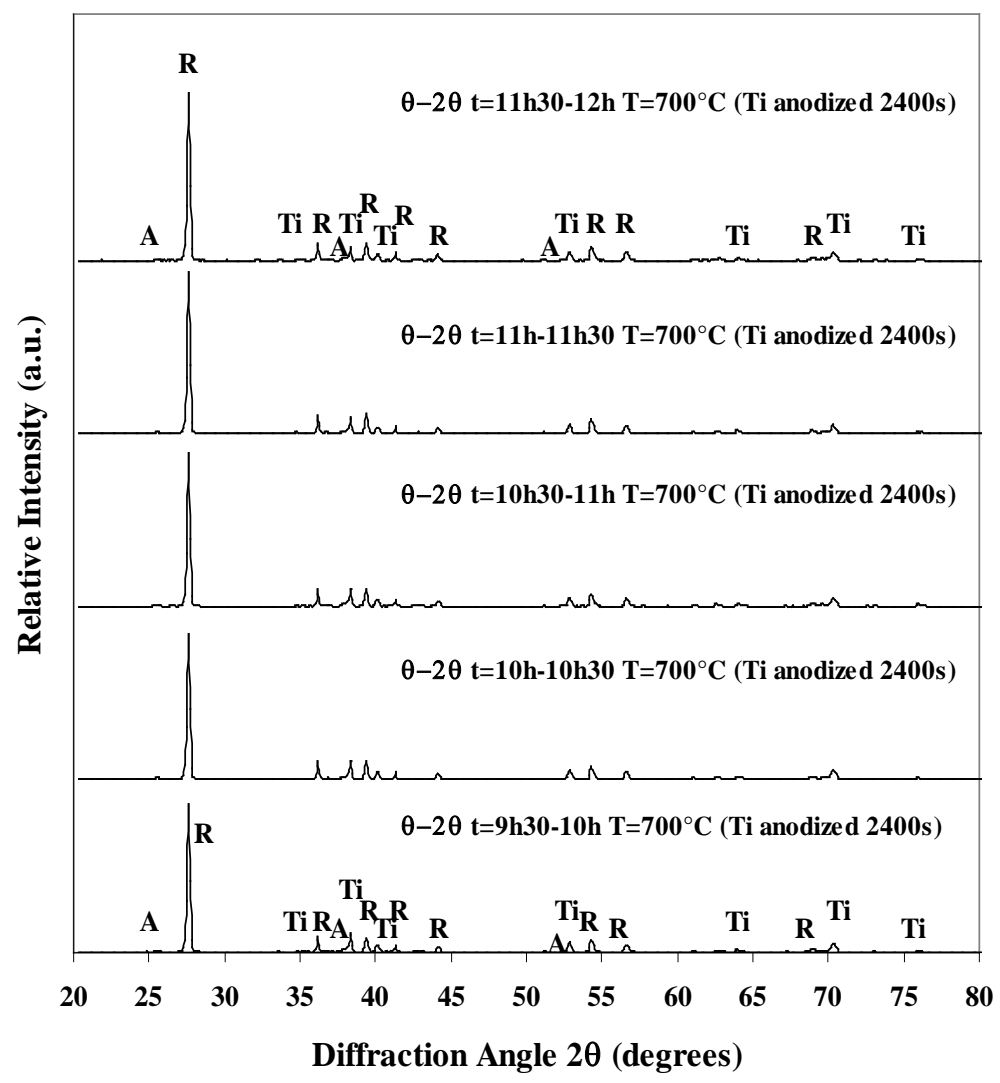

Figure 9. In-situ high-temperature XRD experimental diffractograms performed on titanium anodized sample annealed at $\mathrm{T}=700^{\circ} \mathrm{C}$ in air (Ti: titanium, A: anatase, $\mathrm{R}$ : rutile) from $9 \mathrm{~h} 30$ to $12 \mathrm{~h}$.

all along the heat treatment process.

\subsection{Photodegradation Studies of Acid Orange (A07)}

The photo-degradation experiments of $\mathrm{AO} 7$ in the presence of $\mathrm{TiO}_{2}$ nanotubes under different conditions are summarized in Figure 10. The initial concentration of the AO7 is $5.0 \times 10^{-5} \mathrm{~mol} / \mathrm{L}$, at constant $\mathrm{pH}=7$. On Figure 10, curve (c) shows the photo-degradation of $\mathrm{AO} 7$ under $\mathrm{UV}$ light without $\mathrm{TiO}_{2}$. This result shows that the AO7 is not degraded by UV radiation alone. The curve (a) shows that the amount of AO7 in the presence of $\mathrm{TiO}_{2}$ nanotube for $24 \mathrm{~h}$ without UV was $5 \%$ lower. Thus, the effect of the adsorption of the dye on the $\mathrm{TiO}_{2}$ surface is small. The same is also observed for the curve (b) in presence of UV light. The curve (d) illustrates the photodegradation of AO7 after that sample has been anodized during 20 minutes and annealed at $700^{\circ} \mathrm{C}$. We observed a complete disappearance of the AO7 dye after $24 \mathrm{~h}$. This optical result confirms the degradation of the organic molecule under UV irradiations in presence of the annealed nanotubes of $\mathrm{TiO}_{2}$. In this case, the kinetic of degradation of AO7 follows a pseudo-first order and the rate constant is determined at $0.22 \mathrm{~h}^{-1}$.

The Figure 11 shows typical UV-visible spectra obtained during UV irradiation (365 nm) of AO7 in the presence of $\mathrm{TiO}_{2}$ nanotube annealed at $700^{\circ} \mathrm{C}$ and anodized during 20 minutes. These spectra clearly show that the absorbance of the characteristic band of $\mathrm{AO} 7 \mathrm{at} 485 \mathrm{~nm}$ decreases as function of irradiation time. After $22 \mathrm{~h}$ of irradiation, the solution of the AO7 becomes colourless.

\subsection{Photodegradation of 4-Chlorophenol: An Analytical Study}

Upon irradiation of 4-CP with nanotube layer of $\mathrm{TiO}_{2}$, the organic compound disappearance was observed together with the formation of 2 by-products: P1 and P2. The two of them have been formally identified by injecting commercial compounds. The first of them (P1) was identified as hydroxyquinone, and the second (P2) as benzoquinone. The Figure 12 shows the evolution of the 4-chlorophenol, the hydroxyquinone (HQ) and the 


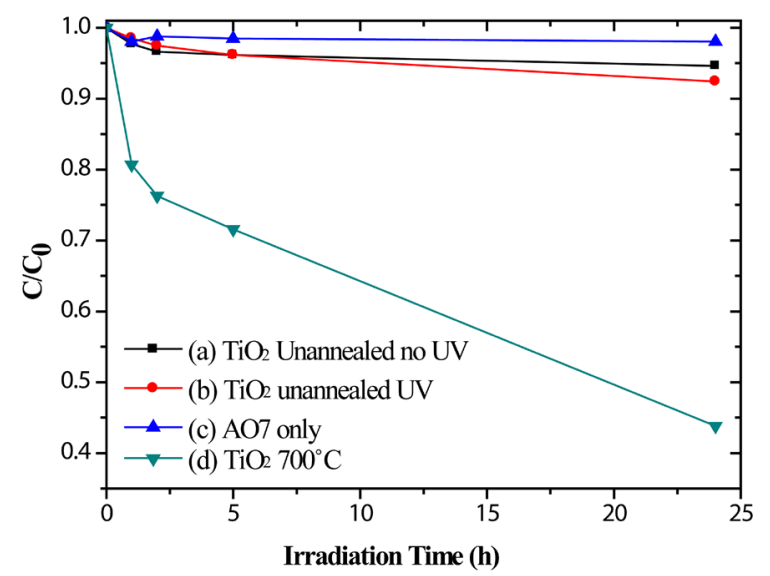

Figure 10. Kinetics of photodegradation of acid orange 7 (AO7) dye under UV lamp irradiation at $365 \mathrm{~nm}$ in the presence of $\mathrm{TiO}_{2}$ nanotube layer, as measured by absorbance of the irradiated dye at $485 \mathrm{~nm}$. (a) $\mathrm{AO} 7$ with $\mathrm{TiO}_{2}$ nanotube layer without UV; (b) Unannealed $\mathrm{TiO}_{2}$ nanotube layer; (c) $\mathrm{AO} 7$ only with $\mathrm{UV}$; (d) $\mathrm{TiO}_{2}$ nanotube layer annealed at $700^{\circ} \mathrm{C}$.

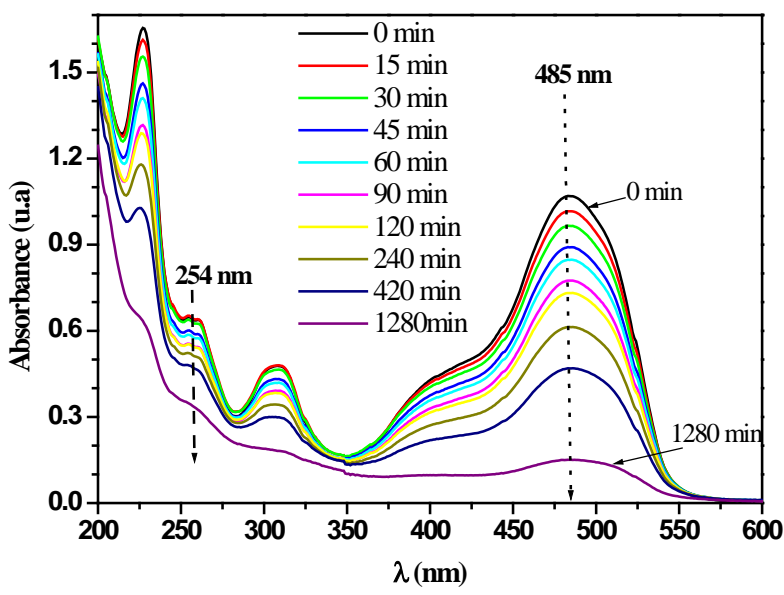

Figure 11. Absorption versus irradiation time for the acid orange (AO7) under irradiation at $365 \mathrm{~nm}$, in the presence of $\mathrm{TiO}_{2}$ nanotube layers annealed at $700^{\circ} \mathrm{C}$ anodized during $20 \mathrm{mi}-$ nutes, with range of exposure time between $0 \mathrm{~min}$ and $1280 \mathrm{~min}$.

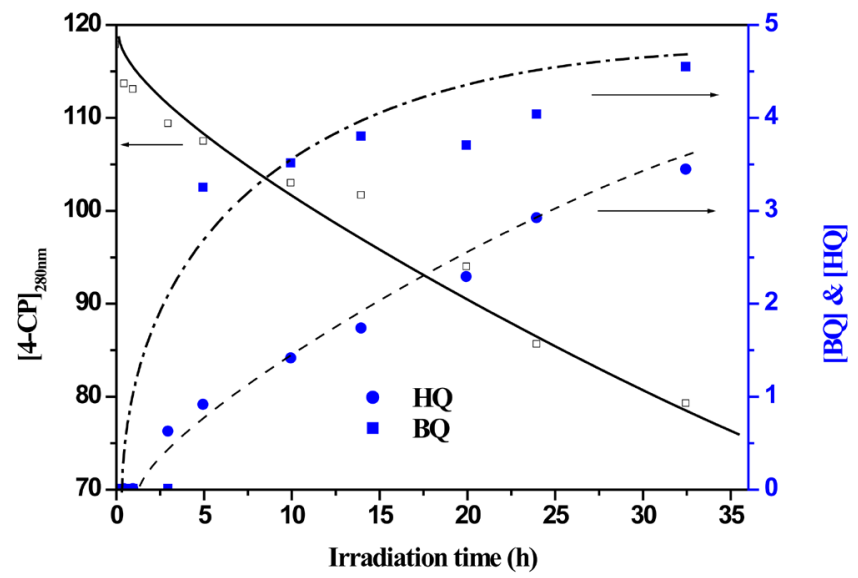

Figure 12. Concentration kinetic of 4-CP ( $\square$ ), benzoquinone $(\square)$ and hydroxyquinone $(\bullet)$ as function of irradiation time. $[4-\mathrm{CP}]=120 \mu \mathrm{M}, \mathrm{TiO}_{2}$ nanotube, annealed at $700^{\circ} \mathrm{C}$, under $\mathrm{UV}$ light irradiation (365 nm). 


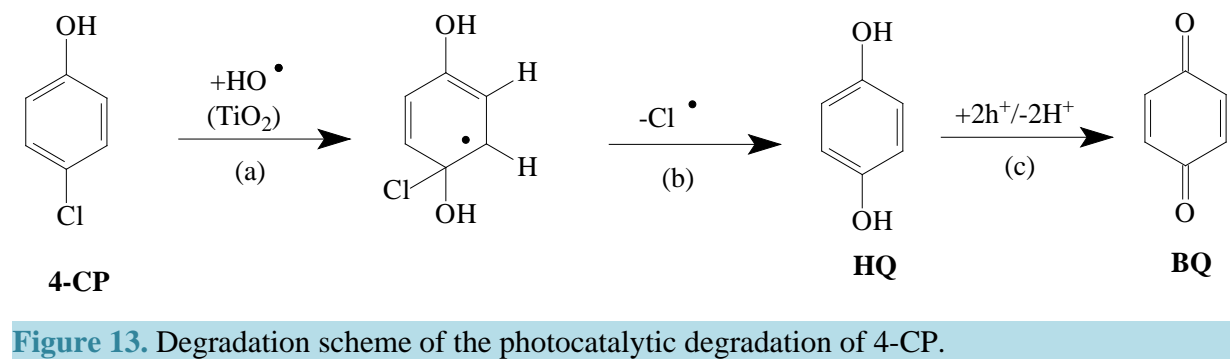

benzoquinone (BQ) versus irradiation time. The both photoproduct are apparently formed with a period of induction (after $2.5 \mathrm{~h}$ of irradiation) and accumulated with irradiation time up to a maximum of $4.5 \mu \mathrm{M}$ for BQ and $3.5 \mu \mathrm{M}$ for $\mathrm{HQ}$ after $35 \mathrm{~h}$. Its concentrations account for over 34\% of 4-chlorophenol degradation.

At the same time, another byproduct is also detected but no possible to quantify. This product is expected to be the hydroxybenzoquinone (HQB) as described in literature [25]. This compound appears at the same time of irradiation as hydroxyquinone (HQ) with the same induction period (after $2.5 \mathrm{~h}$ ).

Taking into account the identification of the byproducts the envisaged pathway of photocatalytic decomposition of 4-chlorophenol is illustrated in Figure 13, in agreement with other work [17]. The first oxidation product of 4-CP is the hydroquinone (HQ) and then the benzoquinone (BQ). The HQ is formed when a hydroxyl radical takes places in para-position (reaction a). Then a chloride ion is released (reaction b). Furthermore, the HQ can be either oxidized to BQ (reaction c).

\section{Conclusions}

This study allows us to follow successfully the oxidation behaviour of titanium dioxide nanotube layers under the annealing treatment. In-situ high temperature X-ray diffraction first reveals, on anodized samples, the building of a substantial amorphous oxide layer, and then the simultaneous growths of anatase and rutile phases occur. Ultimately, initial nucleation stage of rutile and anatase takes place, for the anodized samples, with their normal crystallographic growth orientations, contrary to the heating of the bulk reference sample where nucleation follows the preferential orientation of laminated titanium bulk (002). The initial amorphous oxide layer is responsible for the lower mass gain recorded on the anodized samples compared to bulk material. The external rutile layer, detected after a longer annealing time, induces the parabolic shapes of the mass gain curves.

The photodegradation study of acid orange 7 using annealed nanotubes layer attests the photocatalytic activity of the annealed samples. A complete disappearance of the organic dye after $25 \mathrm{~h}$ of irradiation is recorded. Concerning the photodegradation of 4-chlorophenol, two by-products hydroxyquinone (HQ) and benzoquinone (BQ) are identified by HPLC analysis after a $2.5 \mathrm{~h}$ period of induction. Taking into account the chemical structures of these compounds, this analytical result seems to confirm the reaction pathway often found without experimental evidence in the literature. These results are a contribution to a better understanding of the different crystallization steps of titanium dioxide nanotube layers submitted to the annealing treatment. This work opens the way to the optimization of annealing parameters in order to obtain stable nanostructured layers required to counter corrosion in the field of titanium nanostructured prostheses.

\section{References}

[1] Feynman, R. (1960) There’s Plenty of Room at the Bottom. Engineering and Science, 23, 22-36. http://resolver.caltech.edu/CaltechES:23.5.1960Bottom

[2] Dong, L., Craig, M., Khang, K. and Chen, C. (2012) Applications of Nanomaterials in Biology and Medicine. Journal of Nanotechnology, 2012, Article ID: 816184, 2 p.

[3] Vinayan, B.P., Schwarzburger, N. and Fichtner, M. (2014) Synthesis of a Nitrogen Rich (2D-1D) Hybrid Carbon Nanomaterial Using a $\mathrm{MnO}_{2}$ Nanorod Template for High Performance Li-Ion Battery Applications. Journal of Materials Chemistry A, 3, 6810-6818. http://dx.doi.org/10.1039/C4TA05642F

[4] Galstyan, V., Comini, E., Fagliaa, G. and Sberveglieria, G. (2014) Synthesis of Self-Ordered and Well-Aligned $\mathrm{Nb}_{2} \mathrm{O}_{5}$ Nanotubes. CrystEngComm, 6, 10273-10279. http://dx.doi.org/10.1039/C4CE01540A

[5] Pervez, S., Kim, D., et al. (2014) High Areal Capacity for Battery Anode Using Rapidly Growing Self-Ordered $\mathrm{TiO}_{2}$ Nanotubes with a High Aspect Ratio. Materials Letters, 137, 347-350. http://dx.doi.org/10.1016/j.matlet.2014.09.032 
[6] Birjandinejad, A., Peivandi, M.T., Kachooei, A.R., Razi, A., Amelfarzad, S. and Omidi, K.F. (2014) The Necessity of MRI in Acute and Mild Knee Trauma. Journal of American Science, 10, 1-4.

[7] Roman, I., DoinaTrusca, R., et al. (2014) Titanium Dioxide Nanotube Films: Preparation, Characterization and Electrochemical Biosensitivity towards Alkaline Phosphatase. Materials Science and Engineering: C, 37, 374-382. http://dx.doi.org/10.1016/j.msec.2014.01.036

[8] Kapusta-Kołodziej, J., Tynkevych, O., et al. (2014) Electrochemical Growth of Porous Titanium Dioxide in a Glycerol-Based Electrolyte at Different Temperatures. Electrochimica Acta, 144, 127-135. http://dx.doi.org/10.1016/j.electacta.2014.08.055

[9] Jarosz, M., Pawlik, A., et al. (2014) Effect of the Previous Usage of Electrolyte on Growth of Anodic Titanium Dioxide (ATO) in a Glycerol-Based Electrolyte. Electrochimica Acta, 136, 412-421. http://dx.doi.org/10.1016/j.electacta.2014.05.077

[10] Smith, Y.R., Ray, R., et al. (2013) Self-Ordered Titanium Dioxide Nanotube Arrays: Anodic Synthesis and Their Photo/ Electro-Catalytic Applications. Materials, 6, 2892-2957. http://dx.doi.org/10.3390/ma6072892

[11] Mahajan, V.K., Misra, M., et al. (2008) Self-Organized $\mathrm{TiO}_{2}$ Nanotubular Arrays for Photo Electrochemical Hydrogen Generation: Effect of Crystallization and Defect Structures. Journal of Physics D: Applied Physics, 41, Article ID: 125307. http://dx.doi.org/10.1088/0022-3727/41/12/125307

[12] Oh, H.J., Hock, R., et al. (2013) Phase Transformation and Photocatalytic Characteristics of Anodic TiO $\mathrm{Nanotubular}$ Film. Journal of Physics and Chemistry of Solids, 74, 708-715. http://dx.doi.org/10.1016/j.jpcs.2013.01.008

[13] Kang, X. and Chen, S. (2010) Photocatalytic Reduction of Methylene Blue by $\mathrm{TiO}_{2}$ Nanotube Arrays: Effects of TiO Crystalline Phase. Journal of Materials Science, 45, 2696-2702. http://dx.doi.org/10.1007/s10853-010-4254-5

[14] Verissimo, N.C. and Cremasco, A. (2014) In Situ Characterization of the Effects of Nb and Sn on the Anatase-Rutile Transition in $\mathrm{TiO}_{2}$ Nanotubes Using High-Temperature X-Ray Diffraction. Applied Surface Science, 307, 372-381. http://dx.doi.org/10.1016/j.apsusc.2014.04.040

[15] Awitor, K.O., Rafqah, S., et al. (2008) Photo-Catalysis Using Titanium Dioxide Nanotube Layers. Journal of Photochemistry and Photobiology A: Chemistry, 2-3, 250-254. http://dx.doi.org/10.1016/j.jphotochem.2008.05.023

[16] Hashimoto, K. and Irie, H. (2005) $\mathrm{TiO}_{2}$ Photocatalysis: A Historical Overview and Future Prospects. Journal of Applied Physics, 44, 8269-8285. http://dx.doi.org/10.1143/JJAP.44.8269

[17] Theurich, J., Lindner, M. and Bahnemann, D.W. (1996) Photocatalytic Degradation of 4-Chlorophenol in Aerated Aqueous Titanium Dioxide Suspensions: A Kinetic and Mechanistic Study. Langmuir, 12, 6368-6376. http://dx.doi.org/10.1021/la960228t

[18] Macak, J., Tsuchiya, H., et al. (2007) $\mathrm{TiO}_{2}$ Nanotubes: Self-Organized Electrochemical Formation, Properties and Applications. Current Opinion in Solid Solid State and Materials Science, 11, 3-18. http://dx.doi.org/10.1016/j.cossms.2007.08.004

[19] Gemelli, E. and Camargo, N.H.A. (2007) Oxidation Kinetics of Commercially Pure Titanium. Revista Material, 12, 525-531. http://dx.doi.org/10.1590/s1517-70762007000300014

[20] Tsuchiya, H. and Macak, J.M. (2005) Self-Organized Porous $\mathrm{TiO}_{2}$ and $\mathrm{ZrO}_{2}$ Produced by Anodization. Corrosion Science, 47, 3324-3330. http://dx.doi.org/10.1016/j.corsci.2005.05.041

[21] Calvert, J.G. and Pitts, J.N. (1966) Photochemistry. Journal of the Franklin Institute, 284, 147-148.

[22] Prakasam, H.E., Shankar, K., et al. (2007) A New Benchmark for $\mathrm{TiO}_{2}$ Nanotube Array Growth by Anodization. The Journal of Physical Chemistry C, 111, 7235-7241. http://dx.doi.org/10.1021/jp070273h

[23] Berger, S., Ghicov, A., et al. (2009) Transparent $\mathrm{TiO}_{2}$ Nanotube Electrodes via Thin Layer Anodization: Fabrication and Use in Electrochromic Devices. Langmuir, 25, 4841-4844. http://dx.doi.org/10.1021/la9004399

[24] Macak, J.M., Zlamal, M., et al. (2007) Self-Organized $\mathrm{TiO}_{2}$ Nanotube Layers as Highly Efficient Photocatalysts. Small, 2, 300-304. http://dx.doi.org/10.1002/smll.200600426

[25] Oudjehani, K. and Boule, P. (1992) Photoreactivity of 4-Chlorophenol in Aqueous Solution. Journal of Photochemistry and Photobiology A: Chemistry, 68, 363-373. http://dx.doi.org/10.1016/1010-6030(92)85245-P 


\section{Submit or recommend next manuscript to SCIRP and we will provide best service for you:}

Accepting pre-submission inquiries through Email, Facebook, Linkedin, Twitter, etc A wide selection of journals (inclusive of 9 subjects, more than 200 journals)

Providing a 24-hour high-quality service

User-friendly online submission system

Fair and swift peer-review system

Efficient typesetting and proofreading procedure

Display of the result of downloads and visits, as well as the number of cited articles

Maximum dissemination of your research work

Submit your manuscript at: http://papersubmission.scirp.org/ 